\title{
COMMUNICATION
}

\section{Capitalism and Unfreedom}

When I responded to the request made in the summer of 1993 by the editors of this Review to participate in what they said they hoped would be a lively discussion involving a number of people around Tom Brass's paper which they enclosed, I little suspected that I would be the only participant: or that Brass in his reply would focus neither on the subject matter of his paper nor on my response, but conduct a post-mortem on my writings in the Indian "mode of production" debate of two decades ago (see Brass, IRSH, 40, 1 (1995), pp. 93-117). All one can say is, others who may have been asked as I was by the editors of $I R S H$ but chose not to participate, showed great good sense which I evidently did not. For Brass seized the opportunity of my naivety in taking him seriously enough at all to write on his paper, to abuse me roundly: according to him I am not only "confused", "sentimental", "inconsistent" and "eclectic", but also "bombastic", "anti-Marxist", "chauvinistic", etc., etc. Some of these terms are repeated several times. Reliance on invective, needless to say, always springs from a dearth of rational argument.

There cannot be genuine academic debate under such conditions. My reason for writing at all is to respond to the allegations regarding my integrity contained in a long, mephitic footnote by Brass taking up most of a page (Brass, IRSH, 40 (1995), p. 95, fn. 63) which deals at length with the volume I edited seven years ago under the title Agrarian Relations and Accumulation - the Mode of Production Debate (Oxford University Press, Delhi). It is interesting to see with what great ease Brass here attributes to me those basic values of capitalist society, which I personally have always found the most contemptible: the implacable pursuit of individual gain and individual self-interest. I am supposed by Brass to have so organized the selection and editing of pieces, as to put my own position in a favourable light, and underplay or cut out altogether criticisms of my views. (It does not evidently strike the author that the very fact and nature of such personal allegations tell us a great deal about the one capable of making them.)

Now, genuine intellectual differences, however sharply expressed, are one thing; but the imputation of bad faith to an editor, and the suggestion that she is manipulative and lacks integrity in the choice and editing of papers, is a different matter altogether. This is libel, which is legally actionable in every bourgeois society. There is today a rising barrage of slander and libel against left-wing academics in the Third World who take anti-imperialist positions, emanating from northem universities including by influential Uncle Toms ensconced in chairs there, who advocate globalization and identify with imperialist interests. They are secure in the

International Review of Social History 42 (1997), pp. 459-461 
knowledge that the Third World academics they are defaming are too busy with their own substantive work to pay much heed, and too far away to bother with costly sterling or dollar libel litigation they cannot in any case afford. Brass presumably considers himself to be a Marxist: it is a pity indeed that precisely when Marxists the world over and particularly in developing countries are under scurrilous attack, for his own reasons he has objectively joined this unedifying band.

The facts, which may be verified by any reader who is interested from the Editor of the Economic and Political Weekly, Bombay (hereafter EPW), are as follows. The Sameeksha Trust which oversees that publication took a decision in 1985 to publish in several volumes under the general editorship of one of the trustees, Ashok Mitra, selections of the papers the EPW had carried over the years around each of several interesting Indian debates including the industrial growth debate and the mode of production debate. I was requested in 1986 by Ashok Mitra to prepare a selection not exceeding about 250 printed pages, of the latter debate. Oxford University Press, Delhi, had agreed to print the books and for commercial viability one was told that the length of the volume had to be restricted. Although as a participant in the debate I was reluctant initially to take on the job, I was persuaded by the argument that new generations of Indian students had never heard of the debate at all, by the absence of any accessible selection in India and by the fact that no one else was prepared to put in the effort. A pirated selection had been brought out by Vanguard Publishers from Lahore and a copy had been sent to me, but no copies were available in Indian bookshops.

The question of including in the volume any paper which had not appeared in the EPW did not arise since the entire project was specifically an EPW project, as is obvious from the general editor's Introduction to each volume. (The industrial growth debate too was published some years later and carries exclusively some of the EPW papers, though by that time the page limit had been relaxed.) The choice of the particular EPW papers going into Agrarian Relations and Accumulation was of course in the main mine as the volume editor, as is the case in any edited selection; and it was my judgement which determined what was cut out and what was kept in each paper. (Persons who might not agree with my selection or editing are not precluded, obviously, from bringing out a different unedited selection or indeed even a full collection including the non-EPW papers if they wish to do so.) Since most of the original contributions were wordy, I edited all except two very short pieces which were left untouched, in order to keep within the suggested length for the volume.

When the consent of the authors for including their papers was originally sought by Krishna Raj, Editor of EPW, some like Hamza Alavi and Ashok Rudra wrote to me directly to suggest that including certain pieces of theirs to replace or add to the ones originally listed by me, might be more appropriate; after reflection I concurred. In this sense selection of 
many of the papers included in the volume represented a consensus. The responsibility for sending back the shortened, edited versions to the authors for their approval before final publication rested with the Editor of EPW, from whom I have reconfirmed recently that no one whose paper was included raised any objection regarding the edited version. My overall impression is that contributors were only too glad that the debate was being rescued if only temporarily from oblivion.

Agrarian Relations and Accumulation is a collective effort of all those who took part in its production: an effort undertaken not for any petty self-serving motive, but because they considered the issues raised by the debate to be important enough for there to be an introductory volume for posterity from where interested persons could seek out and read the original papers and additional references if they so wished. Neither the volume editor nor the contributors received any fee or royalties, in order to keep the price affordable for students. This is the case with the other EPW selections as well. If $I$ had to do the job of editing the volume again, I would make exactly the same selection and edit the pieces in the same manner.

Utsa Patnaik 